ఠ

\title{
A simple rescue maneuver for unfolding and centering a tightly rolled graft in Descemet membrane endothelial keratoplasty
}

This article was published in the following Dove Press journal:

Clinical Ophthalmology

24 October 2014

Number of times this article has been viewed

\section{Konstantinos Droutsas ${ }^{1,2}$ \\ Thomas Bertelmann' \\ Frank M Schroeder' \\ Dimitrios \\ Papaconstantinou ${ }^{2}$ \\ Walter Sekundo'}

'Department of Ophthalmology,

Philipps University, Marburg, Germany;

${ }^{2}$ First Department of Ophthalmology,

University of Athens, Medical School

of Athens, Athens, Greece
Correspondence: Konstantinos Droutsas Department of Ophthalmology, Philipps University, Marburg, Baldingerstraße, 35043 Marburg, Germany

Tel +4964215862600

Email konstantinos_droutsas@yahoo.gr

\begin{abstract}
A 74-year-old man underwent Descemet membrane endothelial keratoplasty (DMEK) for endothelial decompensation due to Fuchs endothelial dystrophy. After descemetorhexis, the DMEK graft was inserted into the anterior chamber. However, unfolding of the graft was not possible as the graft was very tightly rolled together and the anterior chamber deep. After placing a 30G-cannula connected to an air-filled syringe inside the roll's lumen, a small air bubble was injected, which allowed the roll to open up, until it assumed a "taco" configuration around the bubble. Then, the graft was centered by pressing the posterior part of the roll against, and sweeping it over the iris. In the present case a "tight" DMEK roll was successfully unfolded by injection of a single air bubble into the roll's lumen and centered by a "sweeping" the partialy unfolded graft over the iris. This technique allowed a controlled unfolding and centering of the DMEK graft with limited trauma to the donor endothelium and may be applied in cases where other less traumatic maneuvers are not successful.
\end{abstract}

Keywords: Fuchs endothelial dystrophy, surgical technique, endothelial keratoplasty

\section{Introduction}

Descemet membrane endothelial keratoplasty (DMEK) is a novel technique in endothelial keratoplasty in which the corneal endothelium is selectively replaced, allowing an almost perfect anatomical restoration of the cornea. Visual rehabilitation after DMEK is therefore fast and often complete. ${ }^{2}$

Although several well-defined maneuvers for unfolding a DMEK graft inside the anterior chamber have been described, ${ }^{3,4}$ atraumatic DMEK may be difficult to achieve, especially when the graft is tightly rolled together. In the present report, we describe a simple rescue maneuver which allows unfolding and centering of a tight DMEK roll in a case in which atraumatic maneuvers were not successful.

\section{Materials and methods}

A 74-year-old man underwent DMEK surgery for endothelial decompensation secondary to Fuchs endothelial dystrophy on his pseudophakic left eye. His preoperative best spectacle-corrected visual acuity was 0.1 . Preparation of the donor tissue was performed immediately before surgery in the operating room by applying the standardized preparation technique ${ }^{1}$ of The Netherlands Institute for Innovative Ocular Surgery (NIIOS). DMEK surgery was performed under general anesthesia using the NIIOS standardized "no-touch" technique. ${ }^{3}$ After removal of the recipient endothelium by descemetorhexis, the DMEK roll was stained with $0.06 \%$ Trypan blue dye (VisionBlue; D.O.R.C. Dutch Ophthalmic Research Center, Zuidland, The 


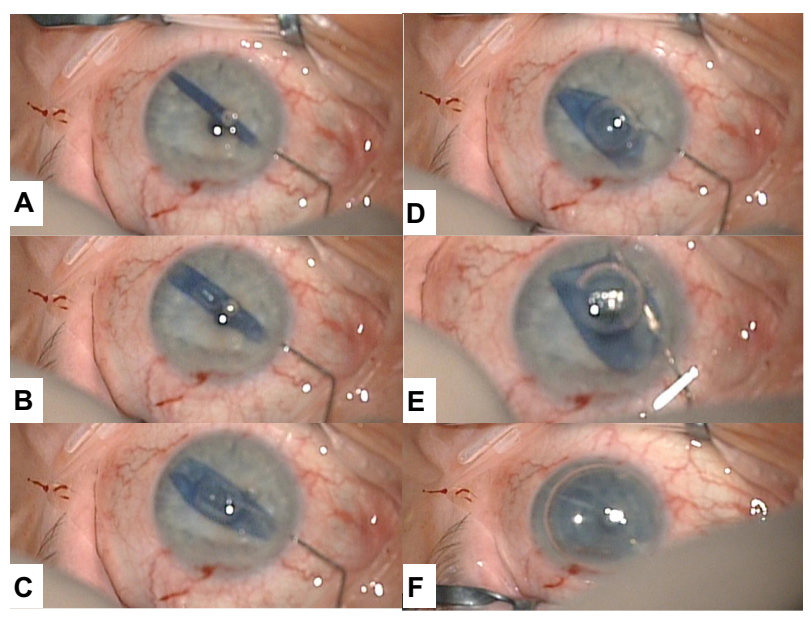

Figure I Stages of the "rescue" maneuver.

Notes: (A) The cannula tip is positioned halfway into the lumen of the tightly rolled Descemet membrane endothelial keratoplasty graft. (B) A small air bubble is injected in a slow and controlled fashion. Note that the bubble is not round, but is nearly cylindrical, conforming to the roll's lumen, due to the high resistance of the graft to being unfolded. (C) The expanding air bubble unfolds the roll. (D) The graft forms a "taco" around the air bubble, with its opening facing the anterior chamber angle. (E) The graft is centered by gently sweeping it with the cannula under the bubble. (F) After removing the air bubble anterior to the graft, another air bubble is injected under the graft in order to lift it against the recipient's cornea.

Netherlands) for 5 minutes and inserted into the anterior chamber using a commercially available glass injector (DMEK surgical disposable set; D.O.R.C.). Then, gentle taps were applied on the corneal surface in order to loosen the roll's tension and allow it to open up. The graft was so tightly rolled together, however, that it not only did not loosen, but rolled immediately back together, even upon forceful injection of balanced salt solution.

In a further attempt, a 30 gauge cannula connected to an air-filled tuberculin syringe was positioned inside the roll's lumen (Figure 1A), and air was slowly injected in order to achieve a controlled opening up of the roll (Figure 1B and C), until it assumed a "taco" configuration around the bubble, with its opening facing the anterior chamber angle (Figure 1D). Then, using a 30 gauge cannula (DMEK surgical disposable set; D.O.R.C.), the graft's periphery was pressed against the iris and centered by sweeping the graft over the iris (Figure 1E). The air bubble was enlarged until the graft was completely unfolded. Finally, the air between the graft and the host cornea was removed and the graft was appositioned against the cornea by injection of another air bubble posterior to the graft (Figure 1F). The eye was left with a maximal air fill at the end of surgery in order to allow adherence of the donor to the host cornea; after 2 hours, a small amount of air was released at the slit lamp by pressing on a side port, in order to avoid an increase of intraocular pressure.

\section{Results}

After 1 week, the cornea was clear and best spectaclecorrected visual acuity was 0.8 ; after 1 month, visual acuity reached 1.0. Endothelial cell density of the donor measured by a specular microscopy (SP2000; TOPCON Corporation, Tokyo, Japan) was 2,303 cells $/ \mathrm{mm}^{2}$ before preparation and 1,986 cells $/ \mathrm{mm}^{2}$ at 1 month, corresponding to an endothelial cell loss of $13.7 \%$.

\section{Discussion}

Recently, several maneuvers for atraumatic unrolling of a DMEK graft have been described: 1) by placing an air bubble on top of the partially unrolled DMEK graft and applying gentle strokes on the corneal surface in order to move the bubble and completely unfold the roll ("Dapena maneuver"); ${ }^{3}$ 2 ) in the case of a shallow anterior chamber, by indenting the cornea with one or two cannulas and then sliding over the corneal surface ("single sliding cannula maneuver", "Dirisamer maneuver"); ${ }^{4} 3$ ) by positioning many small air bubbles into the lumen of the roll; 5 ) in the case of a very deep anterior chamber, by artificially shallowing the anterior chamber through digital impression of the globe and applying the aforementioned cannula maneuvers. ${ }^{6}$

When the anterior chamber is deep and DMEK graft tightly rolled, however, it may remain rolled together and float in the anterior chamber, making controlled atraumatic unfolding difficult. Although unfolding by using air bubbles ${ }^{5}$ and manual centration ${ }^{4}$ has been described in separate papers, this, to the best of our knowledge, is the first report of managing a tightly rolled Descemet membrane by the combination of placing a single air bubble into the roll's lumen followed by manual centration.

Three scenarios may follow the intraluminal injection of air in a floating DMEK roll: 1) the DMEK roll may open toward the cornea. In that case, the graft is correctly oriented as the endothelial side faces the iris, and surgery can be completed by removing the air bubble and placing another air bubble posterior to the unfolded graft; 2) the graft opens toward the anterior chamber angle, then the described "rescue" maneuver can be applied; 3) the graft opens toward the iris. In this case, the graft is pressed by the bubble with the endothelial side against the cornea, that is, upside down. In order to obtain a correct orientation, the air bubble can be removed and the unfolding maneuver may be repeated until the graft is oriented as in 1) or 2). Finally, as the described "rescue" maneuver may be more traumatic than no-touch maneuvers, it may be advisable to use this method only when atraumatic maneuvers fail. 


\section{Disclosure}

The authors report no conflicts of interest in this work.

\section{References}

1. Lie JT, Birbal R, Ham L, van der Wees J, Melles GRJ. Donor tissue preparation for Descemet membrane endothelial keratoplasty (DMEK). $J$ Cataract Refract Surg. 2008;34(9):1578-1583.

2. Droutsas K, Ham L, Dapena I, Geerling G, Oellerich S, Melles G. [Visual acuity following Descemet-membrane endothelial keratoplasty (DMEK): first 100 cases operated on for Fuchs endothelial dystrophy]. Klin Monbl Augenheilkd. 2010;227(6):467-477. German.
3. Dapena I, Moutsouris K, Droutsas K, Ham L, van Dijk K, Melles GR. Standardized "no-touch" technique for descemet membrane endothelial keratoplasty. Arch Ophthalmol. 2011;129(1):88-94.

4. Liarakos VS, Dapena I, Ham L, van Dijk K, Melles GR. Intraocular graft unfolding techniques in descemet membrane endothelial keratoplasty. JAMA Ophthalmol. 2013 Jan;131(1):29-35.

5. Kruse FE, Laaser K, Cursiefen C, et al. A stepwise approach to donor preparation and insertion increases safety and outcome of Descemet membrane endothelial keratoplasty. Cornea. 2011;30(5):580-587.

6. Yoeruek E, Bayyoud T, Hofmann J, Bartz-Schmidt KU. Novel maneuver facilitating Descemet membrane unfolding in the anterior chamber. Cornea. 2013;32(3):370-373.
Clinical Ophthalmology

\section{Publish your work in this journal}

Clinical Ophthalmology is an international, peer-reviewed journal covering all subspecialties within ophthalmology. Key topics include: Optometry; Visual science; Pharmacology and drug therapy in eye diseases; Basic Sciences; Primary and Secondary eye care; Patien Safety and Quality of Care Improvements. This journal is indexed on

Submit your manuscript here: http://www.dovepress.com/clinical-ophthalmology-journal

\section{Dovepress}

PubMed Central and CAS, and is the official journal of The Society of Clinical Ophthalmology (SCO). The manuscript management system is completely online and includes a very quick and fair peer-review system, which is all easy to use. Visit http://www.dovepress.com/ testimonials.php to read real quotes from published authors. 